\title{
Activation of liver $X$ receptor promotes fatty acid synthesis in goat mammary epithelial cells via modulation of SREBP1 expression
}

\author{
H. F. Xu, ${ }^{1}$ J. Luo, ${ }^{2 *}$ X. Y. Zhang, ${ }^{2}{ }^{2} . \mathrm{Li}{ }^{3}$ and M. Bionaz ${ }^{4 *}$ \\ ${ }^{1}$ College of Animal Science and Veterinary Medicine, Henan Agricultural University, Zhengzhou, Henan, 450046, P. R. China \\ ${ }^{2}$ Shaanxi Key Laboratory of Molecular Biology for Agriculture, College of Animal Science and Technology, Northwest A\&F University, Yangling, \\ Shaanxi, 712100 , P. R. China \\ ${ }^{3}$ College of Animal Science and Technology, Henan University of Animal Husbandry and Economy, Zhengzhou, Henan, 450046, P. R. China \\ ${ }^{4}$ Department of Animal and Rangeland Sciences, Oregon State University, Corvallis 97331
}

\section{ABSTRACT}

In bovine mammary tissue and cells, liver X receptor (LXR) regulates lipid synthesis mainly via transactivation of the transcription factor sterol regulatory element binding protein 1 (SREBP1). In the present work, we investigated the role of LXR in controlling lipid synthesis via transactivation of SREBP1 in goat primary mammary cells (GMEC). The GMEC were treated with a synthetic agonist of LXR, T0901317, and transactivation and transcription of SREBP1, expression of lipogenic genes, and fatty acid profiling and triacylglycerol (TAG) content of the cells were measured. A mild increase in the mRNA expression level of LXR $\alpha(N R 1 H 3)$ was observed following treatment with different concentrations of T0901317, and a dosedependent increase in mRNA and transactivation of SREBP1 was detected. Activation of LXR resulted in a significant increase in the mRNA expression of most of the measured genes related to de novo synthesis, desaturation, and transport of fatty acids; TAG synthesis; and transcription regulators. Compared with the control, total content of cellular TAG increased by more than $20 \%$ with T0901317 treatment. Furthermore, addition of T0901317 increased the proportion of unsaturated fatty acids (e.g., C16:1, C18:1, C20:1, and C22:1), and decreased the proportion of saturated fatty acids (e.g., C16:0, C18:0, C20:0, and C22:0). These results provide evidence that LXR regulates the expression and activity of SREBP1. Our results indicated that LXR participate in regulating the transcription of genes involved in milk fat synthesis in GMEC in an SREBP1-dependent fashion.

\footnotetext{
Received August 10, 2018.

Accepted December 12, 2018.

*Corresponding authors: luojun@nwsuaf.edu.cn and massimo. bionaz@oregonstate.edu
}

Key words: liver X receptor, SREBP1, lactation, lipid synthesis, milk fat

\section{INTRODUCTION}

Liver X receptors (LXR) are ligand-dependent nuclear receptors with important roles in regulating lipid homeostasis in rodents and mammals (Chen et al., 2004; Darimont et al., 2006; Oppi-Williams et al., 2013). Liver X receptors form obligate heterodimers with retinoid X receptors (RXR) and are bound and activated by oxysterols (Mangelsdorf et al., 1995; Lehmann et al., 1997). Numerous studies revealed that LXR-RXR heterodimer serves as a key regulator of cholesterol homeostasis through initiating the expression of cholesterol $7 \alpha$-hydroxylase, cholesterol ester transfer protein, and ATP-binding cassette transporter 1 (Peet et al., 1998; Russell, 1999; Luo and Tall, 2000; Repa et al., 2000b). Although 2 isoforms of LXR have been characterized in rodents, modulation of LXR $\alpha$ but not LXR $\beta$ affected the expression of key lipogenic enzymes (Peet et al., 1998; Darimont et al., 2006; Zhang et al., 2014). For ruminants, it has been reported that LXR $\beta$ is the predominant subtype in regulating lipid synthesis gene expression (Shi et al., 2017).

Sterol regulatory element binding protein 1 (SREBP1) is a transcription factor with key roles in regulating lipid metabolism. To date, 3 isoforms of the SREBP family have been identified in mammals: SREBP1a, SREBP1c, and SREBP2. The SREBP1a and SREBP1c isoforms are alternative transcripts of $S R E B F 1$, whereas SREBP2 is transcribed from a separate gene (SREBF2). Both isoforms of SREBP1 participate in the regulation of fatty acid synthesis (Tontonoz et al., 1993; Foretz et al., 1999; Eberlé et al., 2004), whereas SREBP2 mainly regulates the synthesis of cholesterol (Tontonoz et al., 1993; Shimano, 2001; Horton et al., 2002).

Sterol regulatory element binding proteins are synthesized as precursor proteins residing in the membranes 
of the endoplasmic reticulum and nuclear envelope complexed with the SREBP cleavage activate protein (SCAP). When the concentration of cholesterol is high, the SCAP is bound to insulin induced gene (INSIG) protein, which anchors the SREBP-SCAP complex to the endoplasmic reticulum or nuclear envelope. When the intracellular cholesterol concentration is low, the INSIG releases the binding of SCAP, allowing the SCAP to chaperone the SREBP to the Golgi apparatus. In the Golgi, the complex goes through 2 steps of proteolytic cleavage by the action of site 1 protease and site 2 protease to release the mature form of SREBP1 protein (N terminus bHLH-Zip active fragment), which contains a nuclear localization signal. The mature SREBP1 enters the cell nucleus to modulate transcription of itself and various lipogenic genes (Horton et al., 2003; Raghow et al., 2008).

As one of the major lipid-synthesizing organs, the lactating mammary gland synthesizes a great amount of triacylglycerol (TAG; Wakil and Abu-Elheiga, 2009; Rudolph et al., 2010). Investigations into the regulation of milk fat synthesis have established SREBP1 as a central hub in the regulation of fatty acid synthesis in the bovine mammary gland (Bauman et al., 2006; Harvatine et al., 2009). In dairy cows, the decrease in activity and expression of SREBP1 by intermediates of the rumen biohydrogenation of PUFA is considered one of the main mechanisms involved in the diet-induced milk fat depression (Bauman et al., 2006). Recent in vitro data provided additional support for the critical role of SREBP1 in controlling expression of genes coding for proteins involved in fatty acid synthesis and uptake in bovine mammary epithelial cells ( $\mathrm{Ma}$ and Corl, 2012). However, SREBP1 is not the only transcriptional regulator of milk fat synthesis. Evidence has mounted to support a role of a network of transcription factors encompassing peroxisome proliferator activated receptor $\gamma(\mathbf{P P A R} \gamma)$, SREBP1, and LXR $\alpha$ regulating the expression of milk fat synthesis-related genes (Bionaz et al., 2015; Osorio et al., 2016).

The regulatory function of PPAR $\gamma$ on lipid accumulation has been demonstrated to be mediated by perilipin in mammary epithelial cells of dairy goats (Shi et al., 2014; Kang et al., 2015). The role of LXR in controlling milk fat synthesis was initially demonstrated by work conducted in bovine mammary cells in vitro, where activation of LXR $\alpha$ by the specific agonist T0901317 increased the expression of SREBP1 and augmented de novo fatty acid synthesis (McFadden and Corl, 2010). Since then, much work has been done to clarify the transcriptional regulation mechanism of LXR on SREBP1 and the consequence on milk fat synthesis in ruminants (Wang et al., 2012; Oppi-Williams et al.,
2013; Li et al., 2015b; Yao et al., 2016; Shi et al., 2017). However, much work remains to be done to determine whether the activation of LXR affects the network of genes involved in milk fat synthesis (Bionaz and Loor, 2008). Our hypothesis is that LXR plays a central role in controlling the expression of milk fat synthesisrelated genes and increasing intracellular triglycerides synthesis, likely through increasing the expression of $S R E B F 1$. The objective of the present work was to address the role of LXR in goat milk fat synthesis by using an in vitro approach.

\section{MATERIALS AND METHODS}

The Animal Care and Use Committee of Northwest A\&F University of Agriculture and Technology (Yangling, Shaanxi, China) approved all experimental procedures involving dairy goats.

\section{Cell Culture and Treatments}

Three independent biological replicates were performed for every experiment that is presented. Three healthy 3-yr-old Xinong Saanen dairy goats in the peak lactating period (60 d after parturition) from the experimental farm of Northwest A\&F University were selected and used for the present study. The goat mammary epithelial cells (GMEC) were isolated and cultured as previously described (Lin et al., 2013). Basal culture medium consisted of Dulbecco's modified Eagle's medium/F12 medium (HyClone Laboratories, Beijing, China) supplemented with $10 \%$ fetal bovine serum (HyClone), $5 \mu \mathrm{g} / \mathrm{mL}$ insulin (Sigma, St. Louis, MO), $5 \mathrm{mg} / \mathrm{L}$ hydrocortisone (Sigma), $10 \mathrm{kU} / \mathrm{L}$ penicillin-streptomycin (Harbin Pharmaceutical Group Co. Ltd., Harbin, China), and $10 \mathrm{ng} / \mathrm{mL}$ epidermal growth factor (Gibco Products International Inc., Langley, OK). The GMEC were cultured at $37^{\circ} \mathrm{C}$ with $5 \% \mathrm{CO}_{2}$.

Before the experiments, cells (at passage 5) were seeded in 6-well plates (Corning Inc., Corning, NY) at a density of $2 \times 10^{4}$ cells $/ \mathrm{cm}^{2}$. Twenty-four hours before treatments (approximately 90\% confluence), cells were switched to lactogenic medium supplemented with $2.0 \mu \mathrm{g} / \mathrm{mL}$ prolactin (Sigma) to induce differentiation. Cells were cultured in the lactogenic medium for 24 $\mathrm{h}$ before initiation of the treatments. Differentiated GMEC were incubated with T0901317 at 0, 0.01, 0.1, and $1.0 \mu \mathrm{M}$ for $48 \mathrm{~h}$ (final concentration, dissolved in dimethyl sulfoxide, DMSO; Sigma). The control group $(0 \mu M)$ was treated with the same amount $(1 \mu \mathrm{L} / \mathrm{mL}$ medium) of DMSO as the T0901317-treated group. All treatments were repeated 3 times. 
Total RNA Extraction, Purification, and Quantitative Reverse-Transcription PCR

Total RNA of cells treated with $1 \mu M$ T0901317 or control was isolated using an RNA Prep Pure Cell/ Bacteria Kit (Tiangen Biotech Co. Ltd., Beijing, China) according to the manufacturer's procedures. The RNA concentration and purity were measured and determined using a NanoDrop 2000 spectrophotometer (Thermo Fisher Scientific Inc., Wilmington, DE). The RNA integrity was assessed by electrophoretic analysis of $28 \mathrm{~S}$ and $18 \mathrm{~S}$ rRNA subunits; results showed that the ratio of $28 \mathrm{~S}: 18 \mathrm{~S}$ was approximately 2:1 (Supplemental Figure S1, https://doi.org/10.3168/jds.2018 -15538). The first-strand cDNA was synthesized (500 ng of RNA/10 $\mu \mathrm{L}$ reaction) using a PrimeScript RT Reagent Kit (Takara Bio Inc., Otsu, Japan) according to the manufacturer's instructions. Quantitative reverse-transcription PCR (RT-qPCR) was performed using SYBR Premix Ex Taq (Takara Bio Inc.) and 0.5 $\mu M$ gene-specific primers in a $10-\mu \mathrm{L}$ reaction containing $100 \mathrm{ng}$ of cDNA on a CFX96 Real-Time PCR Detection System (Bio-Rad, Hercules, CA) according to the manufacturer's instructions. The amplification conditions were as follows: 1 cycle at $95^{\circ} \mathrm{C}$ for $30 \mathrm{~s}$, followed by 39 cycles at $95^{\circ} \mathrm{C}$ for $5 \mathrm{~s}$ and $60^{\circ} \mathrm{C}$ for $30 \mathrm{~s}$; a dissociation curve of each sample was performed at $95^{\circ} \mathrm{C}$ for $10 \mathrm{~s}$ and then from $65^{\circ} \mathrm{C}$ to $95^{\circ} \mathrm{C}$ with an increment of $0.5^{\circ} \mathrm{C}$. Gene-specific primers for RT-qPCR were designed using Primer Premier 5 (Premier Biosoft, Palo Alto, CA; Supplemental Table S1, https://doi.org/10 $.3168 /$ jds.2018-15538).

The RDML files were exported and uploaded into LinRegPCR software for RT-qPCR quantification analysis (Ramakers et al., 2003). LinRegPCR allows users to obtain final values corresponding to a relative abundance of the transcript that can be used for statistical analysis; however, those values were corrected by dividing for a normalization factor. The normalization factor was calculated as the geometrical mean of the RT-qPCR data obtained from LinRegPCR analysis of mitochondrial ribosomal protein L39 (MRPL39), ribosomal protein S9 (RPS9), and ubiquitously expressed transcript $(U X T)$. The stability of the internal control genes and the reliability of the calculated normalization factor were evaluated using geNorm (Vandesompele et al., 2002). The $M$-value was $<0.28$ for all 3 internal control genes, and the $V$-value was $\leq 0.07$; thus, all 3 internal controls were very stable and the normalization factor was reliable according to the threshold suggested by Vandesompele et al. (2002; i.e., $\leq 1.5$ for $M$-value and $\leq 0.15$ for $V$-value).

\section{Oil Red O Staining}

After $48 \mathrm{~h}$ of incubation with 0 or $1 \mu M$ T0901317, normal GMEC were rinsed twice with cold PBS and fixed with $10 \%$ pre-cold paraformaldehyde for $1 \mathrm{~h}$ at $4^{\circ} \mathrm{C}$. Fixed cells were rinsed twice in PBS and stained with a freshly working solution of Oil Red O (Sigma, St. Louis, MO; 0.5\% Oil Red O dissolved in isopropanol: deionized water $=2: 1$ ) for 40 min at room temperature under gentle shaking. Finally, cells were rinsed 3 times with cold PBS to remove the Oil Red $\mathrm{O}$ residues and observed under a Leica DMI4000B inverted fluorescence microscope (Leica Geosystems Co. Ltd., Norcross, GA; Lin et al., 2013; Li et al., 2015a). Two pictures per well were taken, and quantification of Oil Red O images was carried out using ImageJ software (http://imagej.nih .gov/ij/) by transforming the figures in 8-bit (threshold at 200 to 250) and measuring the percentage of area covered by the Oil Red O.

\section{Quantification of Total Cellular TAG}

After $48 \mathrm{~h}$ of incubation with 0 or $1 \mu M$ T0901317, cells were rinsed 3 times with PBS and then harvested in lysis buffer (50 mM Tris-HCL, pH 7.4, $150 \mathrm{mM} \mathrm{NaCl}$, $1 \%$ Triton X-100), and cells were scraped off the culture dish and sonicated to homogenize the cell suspension. Intracellular total TAG was measured according to the GPO-Trinder Triglyceride Assay Kit (Applygen Technologies Inc., Beijing, China). The concentration of TAG was determined on a microtiter plate reader (Bio-Rad) and normalized to total cellular protein assessed using a BCA protein assay (Thermo Fisher Scientific) according to the manufacturer's instructions (Kang et al., 2015).

\section{Fatty Acid Analysis}

Normal GMEC seeded in 60-mm culture dish (Corning Inc.) were incubated with DMSO or $1 \mu M$ T0901317 in DMSO for $48 \mathrm{~h}$ after 24 -h induction of lactation. Total lipid was extracted according to Zhu et al. (2014). Briefly, cells were washed twice with PBS and scraped into a $1.5-\mathrm{mL}$ tube, followed by $5 \mathrm{~min}$ of shaking and 5 min of centrifugation at 1,200 $\times g$. Total fatty acids were extracted from approximately $100-\mathrm{mg}$ cells using $2 \mathrm{~mL}$ of sulfuric acid:methanol (2.5:1 vol/ vol) and used for fatty acid analysis by GC-MS (Trace GC ultra-DSQII-AI3000; Thermo Fisher Scientific) using a BP-5MS $(30 \mathrm{~m} \times 0.25 \mathrm{~mm} \times 0.25 \mu \mathrm{m})$ column. A commercial C19:0 was used as an internal control. The relative proportions of each fatty acid were determined 
as percentages of the total peak areas that could be identified (Wang et al., 2012; Takahashi et al., 2013). This experiment was performed with 3 biological replicates.

\section{Plasmid Construction, Transfection, and Luciferase Assay}

Goat SREBP1c promoter $[-2,012 \mathrm{bp} \sim+1 \mathrm{bp} ; 2$ sterol response elements were located in $-97 \mathrm{bp}$ to $-116 \mathrm{bp}$ and $-809 \mathrm{bp}$ to $-817 \mathrm{bp}$, respectively; 2 LXR response elements were located in $-220 \mathrm{bp}$ to $-235 \mathrm{bp}$ and $-271 \mathrm{bp}$ to $-286 \mathrm{bp}$, respectively; +1 indicates the transcriptional start site (TSS), - means the upstream sequence of TSS, and + means the downstream sequence of TSS] was cloned from goat genomic DNA using LA Taq Polymerase and $2 \times$ GC buffer I (Takara Bio Inc.) following a previously published protocol (Lengi and Corl, 2010). Primers used were as follows: forward, 5'-GGGAGATTTGAAGGTAGAGC-3'; reverse, 5'-GGCACCGAGGATGGAAC-3'. The resulting amplicon was cloned into pMD19-T vector for sequencing and then subcloned into the pGL3-Basic vector (Promega, Madison, WI) by using KpnI (Takara Bio Inc.) and HindIII (Takara Bio Inc.) enzyme sites.

The DNA transfection of GMEC was performed with X-Treme Gene HP DNA Transfection Reagent (Roche China Ltd., Shanghai, China). The GMEC at $80 \%$ confluence in a 48-well plate were transiently transfected with $200 \mathrm{ng}$ of pGL3-SREBP1c reporter plasmid along with $4 \mathrm{ng}$ of Renilla vector as a control to normalize transfection efficiency (Kang et al., 2015) and then incubated with T0901317 at final concentration of 0, $0.01,0.1,1,2$, and $10 \mu M$ T0901317. After $48 \mathrm{~h}$ of incubation, cells were harvested and lysed for luciferase activity measurement using a Dual-Luciferase Reporter Assay System according to the manufacturer's instructions (Promega). Each treatment was repeated in 3 replicates.

\section{Statistical Analysis}

All treatments were conducted in triplicate. Data from each sample were divided by the mean of the control group to obtain a mean of 1 for the control group and a fold change relative to the control for the treatments. This transformation allowed us to better visualize the results, maintaining the variation in the control as untransformed data for statistical comparisons. Transformed data were checked for normal distribution using the Univariate procedure of SAS (version 9.4, SAS Institute Inc., Cary, NC) prior to the statistical analysis. For unequally spaced dose-effect analysis, we used the IML procedure with ORPOL in association with GLM with orthogonal contrasts to obtain linear and quadratic effects. For the RT-qPCR analysis, the data were further transformed in natural logarithm before statistical analysis. This was performed using the GLM procedure of SAS with treatment as main effect and replicate as random effect. Differences were considered statistically significant when $P \leq 0.05$, and data were reported as least squares means \pm standard error.

\section{RESULTS}

\section{Activation of LXR by T0901317 Increases Transcription of SREBP1}

After treatment with T0901317, the transcription activity of SREBP1 increased in a dose-dependent manner as observed in Figure 1. The increase reached a peak and a plateau with $1 \mu M$ T0901317.

When normal (i.e., nontransfected) GMEC were treated with $1 \mu M$ T0901317, we detected a moderate but significant increase in mRNA expression level of LXR $\alpha$ (Figure 2A) and a large increase in mRNA abundance of SREBF1. The increase in SREBF1 was almost exclusively due to the increase in expression of SREBF1A (Figure 2B and C).

\section{Activation of LXR Enhances the Expression of Fatty Acid- and TAG Synthesis-Related Genes in GMEC}

The mRNA abundance of solute carrier family 27 member 6 (SLC27A6), fatty acid binding protein 3 (FABP 3$)$, and acyl-CoA synthase long-chain family member 1 (ACSL1), coding for proteins responsible for long-chain fatty acid transport and activation, were all upregulated by the agonist of LXR (Figure 3A), with the largest increase observed in stearoyl-coenzyme A desaturase 1 ( $\boldsymbol{S C D 1}$ ). Similarly, the mRNA abundance of all the genes measured coding for enzymes involved in de novo fatty acid synthesis was upregulated by the activation of LXR (Figure 3B). These included fatty acid synthase $(\boldsymbol{F A S N})$, acetyl-CoA carboxylase a $(\boldsymbol{A} \boldsymbol{C A} \boldsymbol{C A})$, ATP citrate lyase $(A C L Y)$, acyl-CoA synthetase short-chain family member 2 (ACSS2), and $S C D 1$. The elongation of very long chain fatty acids family member 6 (ELOVL6) and isocitrate dehydrogenase 1 (IDH1), important for the provision of NADPH for fatty acid synthesis, was not affected by the treatment.

As summarized in Figure 3C, treatment with $1 \mu M$ T0901317 increased the mRNA expression of genes responsible for TAG synthesis and lipid droplet formation and secretion: lipin 1 (LPIN1), diacylglycerol O-acyltransferase 2 (DGAT2), perilipin 2 (PLIN2, 


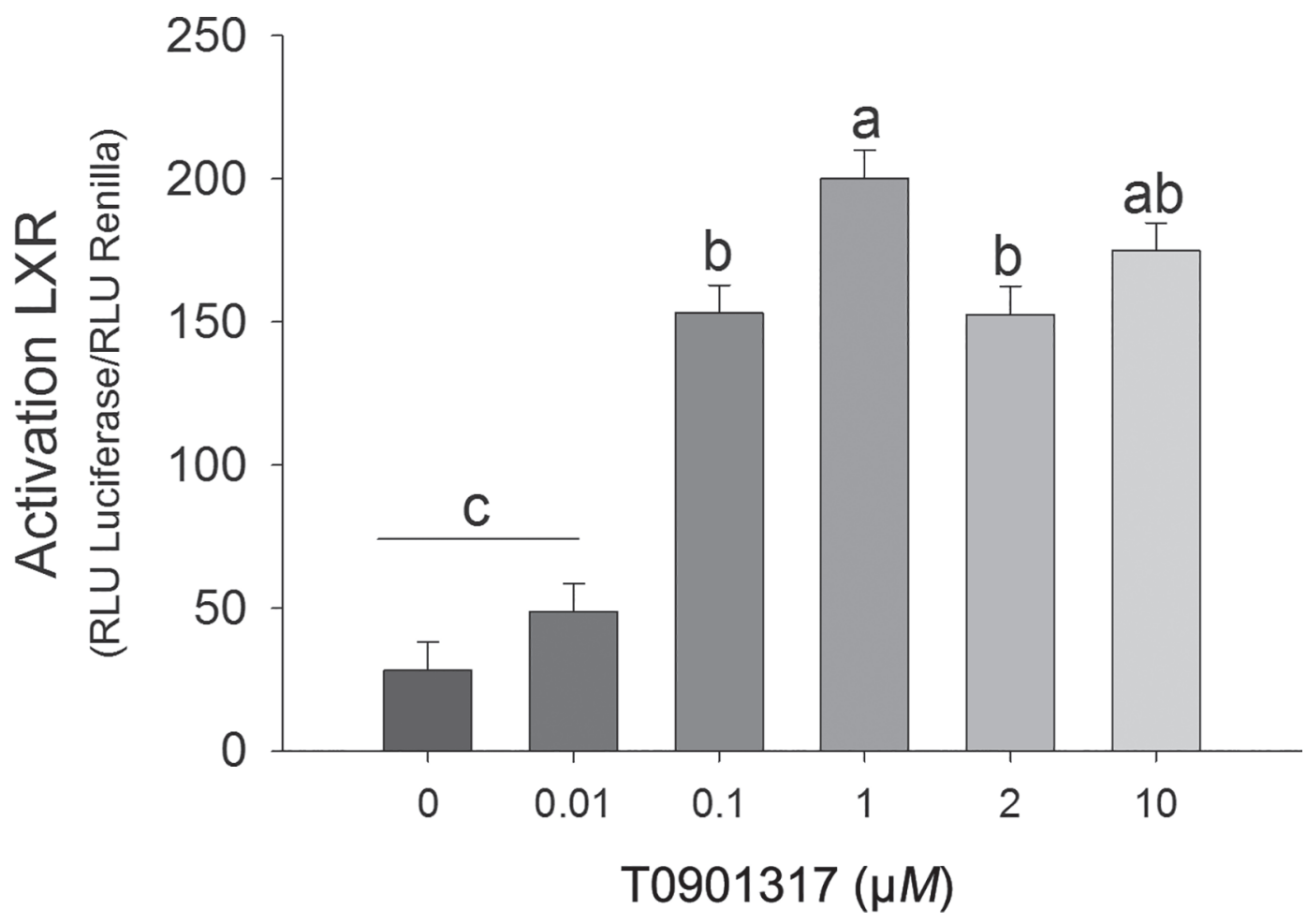

Figure 1. T0901317, a synthetic agonist of liver X receptor (LXR), increases the transactivation of SREBF1 in a dose-dependent manner. Goat mammary epithelial cells were transfected with an SREBP1c promoter plasmid driving luciferase expression and incubated with 0, 0.01, $0.1,1,2$, and $10 \mu M$ T0901317 for $48 \mathrm{~h}$. Significant linear $(P<0.0001)$ and quadratic $(P=0.04)$ effects were detected. RLU $=$ relative light unit. Values are presented as LSM \pm SEM. Different letters $(\mathrm{a}-\mathrm{c})$ denote significant difference at $P<0.05$.

also known as $A D R P)$ and $3(\boldsymbol{P L I N 3}$, also known as TIP47), and adipose triglyceride lipase $(A T G L)$, responsible for the lipid droplet TG depletion. Among the same category of genes, glycerol-3-phosphate acyltransferase 1 ( $\boldsymbol{G P A M}$ ), diacylglycerol O-acyltransferase 1 (DGAT1), and xanthine dehydrogenase $(X D H)$ were not significantly affected by the activation of LXR (Figure 3C).

Among genes involved in transcriptional regulation, only INSIG1 was significantly upregulated by $1 \mu M$ T0901317 treatment, whereas $S C A P$ and $P P A R A$ were not affected and PPARG tended $(P=0.07)$ to be decreased by the activation of LXR (Figure 3D).

\section{T0901317 Increases the Content of Cellular TAG and MUFA}

The activation of LXR by T0901317 increased the amount of lipid droplet containing TAG in cells, as observed with Oil Red O staining (Figure 4A-C). The quantification of TAG revealed a $>1.2$-fold increase in cellular TAG by $1 \mu M$ T0901317 treatment (Figure 4D).

Compared with the control group, T0901317 had a significant effect on the proportion of each long-chain fatty acid in the cells. The proportion of the saturated C18:0 decreased and that of long-chain MUFA, C16:1, cis9-C18:1, C20:1, and C22:1 increased (Table 1). However, the proportion of C18:2 decreased numerically and proportion of PUFA decreased significantly with T0901317 treatment (Table 1).

\section{DISCUSSION}

Studies conducted in rodents have demonstrated that LXR isoforms and SREBP1c work synergistically to increase the synthesis of liver TAG (Repa et al., 2000b; Okazaki et al., 2010). On one hand, LXR enhances fatty acid synthesis largely by activating the transcription of SREBP1c, which in turn transactivates lipogenic genes (Liang et al., 2002; Chen et al., 2004); on the other hand, LXR also directly stimulates the transcription of certain lipogenic genes, including $A C A C A$ in chick embryos (Talukdar and Hillgartner, 2006) and FASN in human cells (Joseph et al., 2002). However, compared with the control group, the increase in mRNA abundance of $A C A C A, S C D 1$, and FASN after treatment with the LXR agonist T0901317 was significantly dampened in SREBP1c knockout mice (Liang et al., 2002). In the same study, the treatment with T0901317 

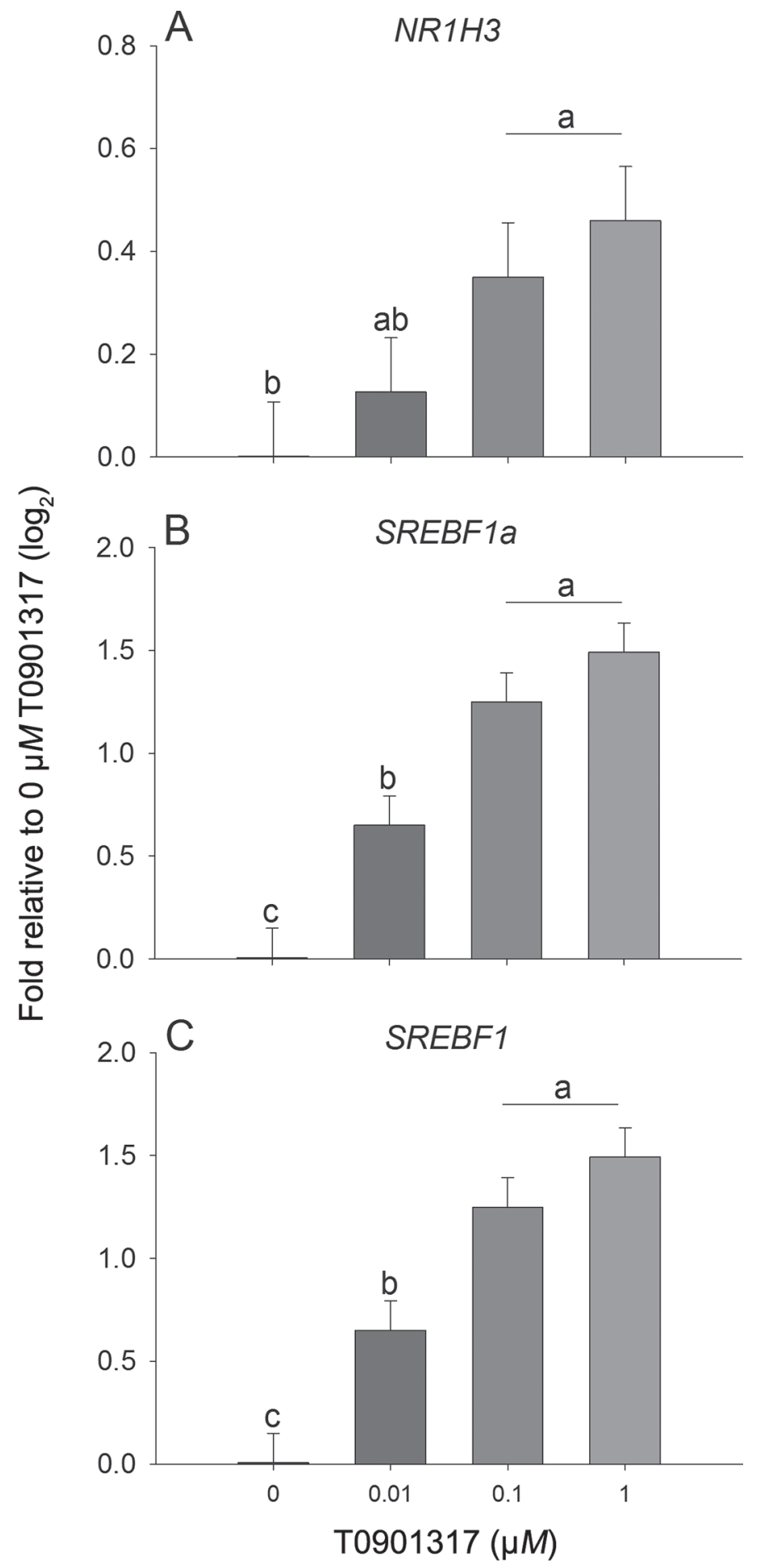

Figure 2. Activation of liver X receptor (LXR) by T0901317, a synthetic agonist of liver $\mathrm{X}$ receptor, increases the transcription of SREBF1. Goat mammary epithelial cells were incubated for $48 \mathrm{~h}$ with dimethyl sulfoxide (DMSO; Sigma, St. Louis, MO; control) or $1 \mu M$ T0901317. (A) The mRNA expression level of NR1H3 (LXR $\alpha$ gene). (B) The mRNA expression level of SREBF1A. (C) The mRNA expression level of $S R E B F 1$. No significant linear effect was observed, but a significant quadratic effect $(P<0.05)$ was detected for all 3 transcripts. Values are presented as LSM \pm SEM. Different letters $(\mathrm{a}-\mathrm{c})$ denote significant difference at $P<0.05$. failed to affect the transcription of Gpam in SREBP1c knockout mice. Mice deficient in LXR $\alpha$ also exhibit reduced expression of SREBP1c and lipogenic genes such as Scd1 and Fasn in the liver (Peet et al., 1998). Taken together, these data indicate that LXR activates fatty acid and TAG synthesis directly or indirectly through SREBP1. Similar to the above findings, the activation of LXR directly increased the expression of lipogenic genes in bovine mammary epithelial cells in an SREBP1-independent fashion (Oppi-Williams et al., 2013). Several studies demonstrated a direct effect of LXR on the expression of $S R E B F 1$ and the downstream genes FASN and SCD1 in goat mammary cells (Li et al., 2015b; Yao et al., 2016). More recent is the demonstration that the LXR $\beta$ also control the expression of SREBP1c and FASN in goat mammary cells (Shi et al., 2017). In rodents, studies underscored a more important role of LXR $\alpha$ and not LXR $\beta$ in regulating lipid metabolism (Repa et al., 2000a; Zhang et al., 2014). We conclude that the leading cause of this difference may be aroused by differences in species and tissues; this needs to be further investigated.

\section{LXR Controls the Expression of SREBP1 in GMEC}

Results from the present study clearly demonstrated that activation of LXR increased the expression of $S R E B F 1$ in a dose-dependent manner, with a relatively modest effect on the mRNA expression level of NR1H3, the LXR $\alpha$-coding gene. The highest transactivation of SREBP1c and expression of SREBF1 was observed when the concentration of T0901317 was $1 \mu M$. Studies on other species have used $2 \mu M$ (Lengi and Corl, 2010; McFadden and Corl, 2010) and $10 \mu M$ (Han et al., 2009; Vedin et al., 2009) T0901317 to activate lipogenic synthesis. The reason for the differences might be due to species differences. However, our data clearly underscore a major role of LXR in controlling the expression of SREBF1 in GMEC, confirming the previous data obtained in bovines and goats. This conclusion is also supported by the presence of 2 LXR binding sites in the promoter region of SREBP1c in bovines and goats (Lengi and Corl, 2010; Xu et al., 2016a).

The SREBP activity is regulated at 2 major levels: transcriptional and posttranslational. Especially important for the latter is the proteolytic cleavage of SREBP precursors to generate the mature (and active) SREBP (Eberlé et al., 2004). Studies on several species demonstrated that insulin regulates the activity of SREBP1 mainly at the transcriptional level (Dif et al., 2006; Owen et al., 2012) and likely through LXR (Chen et al., 2004), whereas other synthetic and natural molecules, such as PUFA, inhibit SREBP1 activity (and, as consequence, expression) by blocking its 
proteolytic cleavage (Harvatine et al., 2009; Kamisuki et al., 2009; Takeuchi et al., 2010). In our study, results of luciferase assay and RT-qPCR suggested an increase of $S R E B F 1$ transcription. To verify whether the change in activation and transcription results in higher protein abundance and activation of SREBP1 (i.e., abundance of the cleaved protein in the nucleus), we ran a Western blot analysis to measure the mature form of SREBP1 using one biological replicate (see description of the method and figure in Supplemental Figure S2, https:// doi.org/10.3168/jds.2018-15538). The data indicated a dose effect on the mature SREBP1 protein abundance
(Supplemental Figure S2); thus, the data indicated both transcriptional and posttranscriptional regulation of SREBP1 by LXR. This is consistent with similar work conducted on bovine cells (McFadden and Corl, 2010). In addition, the expression of the inhibitor of SREBP1 activity, INSIG1, which is also a target gene of SREBP1 (Horton et al., 2003; Xu et al., 2016b), increased only 2.5-fold, indicating that there may be a less than proportional increase in retention of immature SREBP1 in the endoplasmic reticulum. The above observations may support a larger nuclear presence of SREBP1 due to an increase in transcription, but we

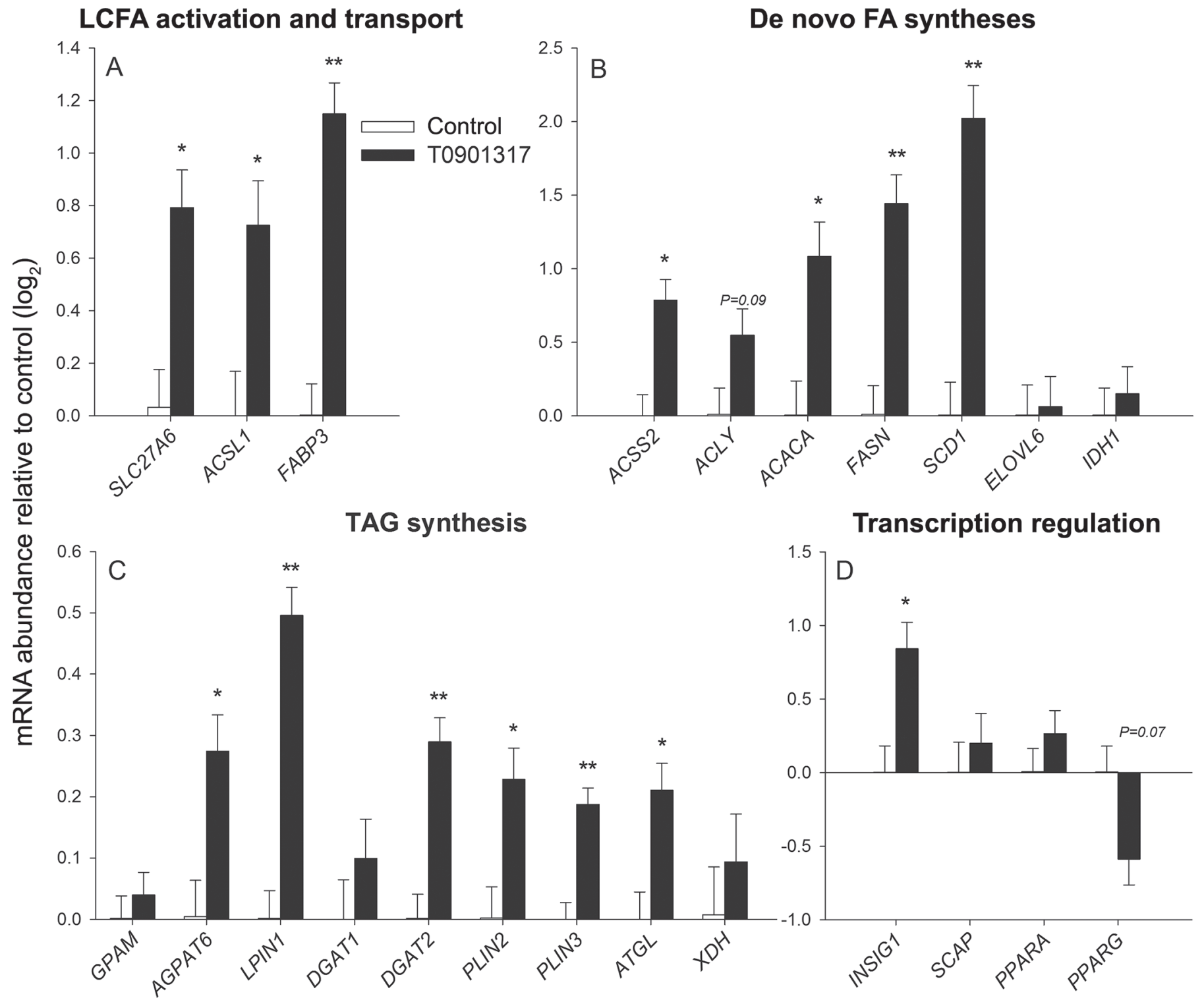

Figure 3. Activation of liver X receptor (LXR) by T0901317, a synthetic agonist of liver X receptor, upregulates the expression of genes coding for key proteins involved in (A) long-chain fatty acid (LCFA) activation and transport, (B) de novo fatty acid (FA) synthesis, (C) triglycerides (TAG) synthesis, and (D) transcription regulation. Values are presented as LSM \pm SEM. ${ }^{*} P<0.05 ;{ }^{* *} P<0.01$. 

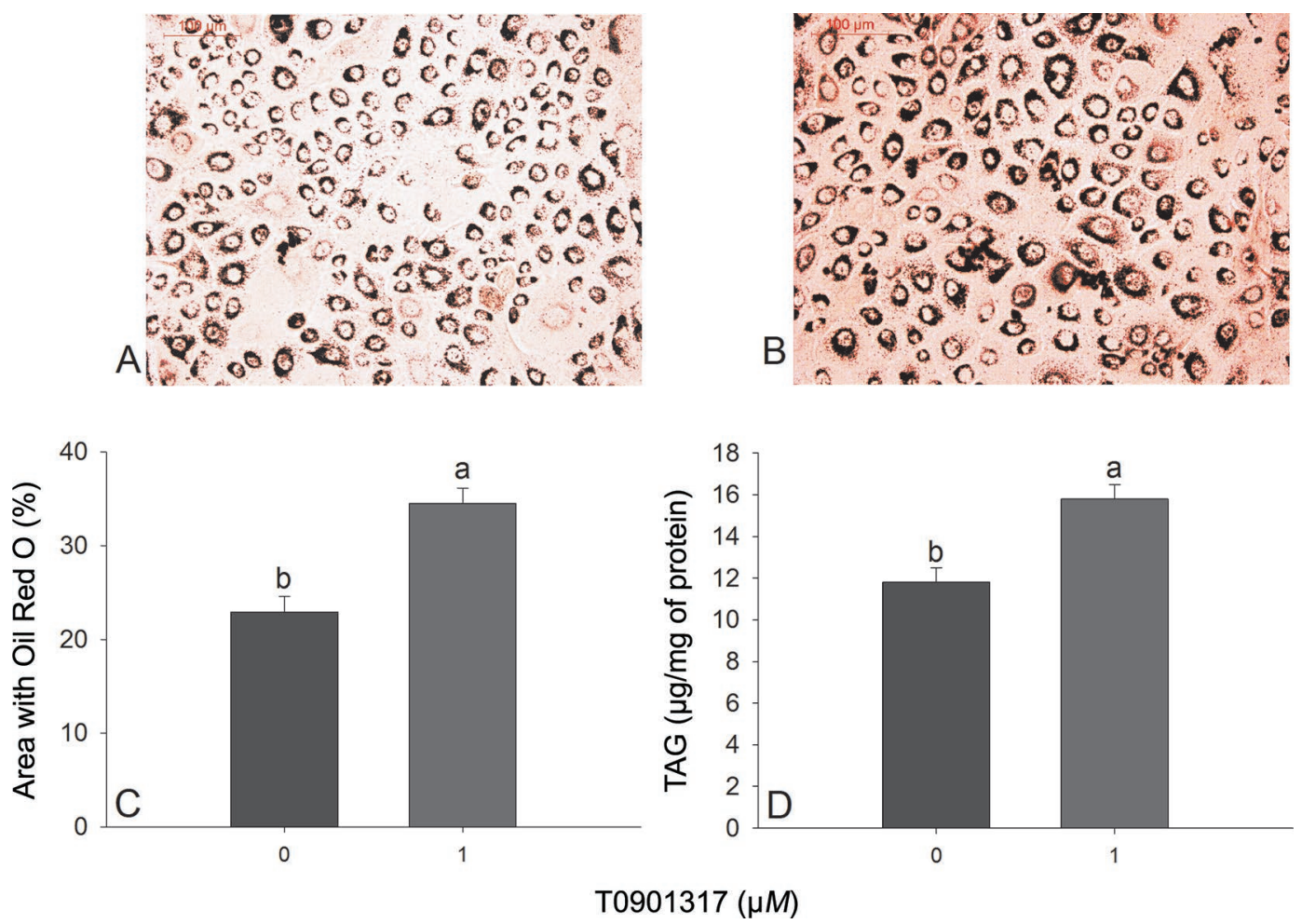

Figure 4. Activation of liver X receptor (LXR) by T0901317, a synthetic agonist of liver X receptor, promotes milk fat droplet and triacylglycerol accumulation in goat mammary epithelial cells. Lipid droplets were stained by Oil Red O: (A) $0 \mu M$ T0901317; (B) $1 \mu M$ T0901317. Scale bar $=100 \mu \mathrm{m}$. (C) Percentage area covered with Oil Red O staining as measured using ImageJ software (http://imagej.nih.gov/ij/). (D) Total cellular triacylglycerol (TAG) content. Values are presented as LSM \pm SEM. Different letters $(\mathrm{a}, \mathrm{b})$ denote significant difference at $P<0.05$.

cannot exclude the possibility that T0901317 indirectly accelerates the proteolytic cleavage process of SREBP1 or enhances the stability of nuclear SREBP1.

\section{LXR Directly and Indirectly Regulates the Expression of Milk Fat Synthesis-Related Genes and Intracellular TAG Synthesis in GMEC}

Milk lipid synthesis and secretion is a complex process that requires the orchestration of a wide variety of proteins (Bionaz and Loor, 2008). Studies to date support SREBP1 playing a primary role in regulating the expression of genes coding for those proteins in human and bovine mammary tissue (Harvatine et al., 2009; Mohammad and Haymond, 2013; Osorio et al., 2016). A role of other transcription factors, especially the ligand-dependent nuclear receptors PPAR $\gamma$ (Bionaz et al., 2013) and LXR (Oppi-Williams et al., 2013; Li et al., 2015b), in controlling the expression of genes involved in milk fat synthesis in bovines and caprines is emerging (Osorio et al., 2016). The receptor PPAR $\gamma$ is a putative or demonstrated upstream transcriptional regulator of most milk fat synthesis-related genes (Bionaz et al., 2013), whereas LXR appears to control milk fat synthesis chiefly through the regulation of $S R E B F 1$ expression. Indeed, this was demonstrated by using SREBF1-specific small interfering RNA (siRNA) in bovine mammary immortalized epithelial cells (Ma and Corl, 2012). Transfection of NR1H3-specific siRNA in Mac-T cells did not affect the mRNA abundance of genes coding for proteins involved in the de novo fatty acid synthesis, indicating that LXR $\alpha$ is not required for basal transcription of genes related to fatty acid synthesis (Oppi-Williams et al., 2013). In contrast, treatment with T0901317 enhanced de novo fatty acid synthesis in bovine mammary epithelial cells (McFadden and Corl, 2010). Furthermore, the activation of LXR $\alpha$ in the presence of an $S R E B F 1$-specific siRNA increased the mRNA abundance of $A C A C A, F A S N$, and DGAT1 but not $S C D 1$ in Mac-T cells (Oppi-Williams et al., 2013), indicating that LXR can regulate milk fat synthesis in an SREBP1-independent fashion. The data also indicate that $S C D 1$ expression is exclusively regulated by SREBP1. Expression of SCD1 was abolished after T0901317 treatment in SREBP1c ${ }^{-/-}$mice (Liang et al., 2002 ). The $>7$-fold increase in mRNA abundance of $S C D 1$ in our study after T0901317 treatment supports $S C D 1$ being an SREBP1 target gene also in GMEC. 
In agreement with these results, we observed large changes in expression of de novo fatty acid synthesisrelated genes (e.g., FASN, ACACA, and SCD1) after T0901317 addition.

It has been previously reported that LXR (Calkin and Tontonoz, 2010; Zhang et al., 2012) and SREBP1 (Ishimoto et al., 2009; Li et al., 2014) activation significantly induces the accumulation of TAG in hepatocytes and cancer cells. Similar to these previous data, our study revealed an overall increase in expression of genes coding for key enzymes responsible for the synthesis of TAG and a larger intracellular accumulation of TAG by T0901317 treatment. Among the TAG synthesis-related genes, LPIN1 and DGAT2 were the most affected by LXR activation (Figure $3 \mathrm{C}$ ).

Lipin 1 modulates TAG accumulation in hepatoblastoma cells (Ishimoto et al., 2009). The same study also identified an SREBP1 response element in the promoter region of LPIN1, indicating direct regulation of LPIN1 by SREBP1. Together with this finding, the increase in expression of LPIN1 after activation of LXR in our study supports this gene being an SREBP1 target in GMEC.

Table 1. Effects of liver X receptor (LXR) activation by T0901317, a synthetic agonist of LXR, on intracellular fatty acid composition in goat mammary epithelial cells

\begin{tabular}{lrrr}
\hline & \multicolumn{2}{c}{ Treatment $^{2}$} & \\
\cline { 2 - 3 } Fatty acid $^{1}(\%)$ & \multicolumn{1}{c}{ Control } & \multicolumn{1}{c}{ T0901317 } & P-value \\
\hline C16:0 & $15.44^{\mathrm{a}} \pm 1.12$ & $13.57 \mathrm{~b} \pm 0.48$ & 0.17 \\
C16:1 & $1.15^{\mathrm{B}} \pm 0.07$ & $2.44^{\mathrm{A}} \pm 0.18$ & $<0.01$ \\
C18:0 & $9.44^{\mathrm{A}} \pm 0.61$ & $5.49^{\mathrm{B}} \pm 0.57$ & $<0.01$ \\
cis-9 C18:1 & $27.13 \pm 0.55$ & $30.15 \pm 0.85$ & 0.05 \\
C18:1 (total) & $30.54^{\mathrm{B}} \pm 0.41$ & $36.81^{\mathrm{A}} \pm 0.29$ & $<0.01$ \\
C18:2 & $1.12 \pm 0.12$ & $0.73 \pm 0.07$ & 0.07 \\
C20:1 & $0.95^{\mathrm{B}} \pm 0.06$ & $1.63^{\mathrm{A}} \pm 0.09$ & $<0.01$ \\
C22:1 & $0.24^{\mathrm{b}} \pm 0.01$ & $0.44^{\mathrm{a}} \pm 0.03$ & 0.01 \\
LCPUFA & $13.98^{\mathrm{a}} \pm 0.92$ & $8.71^{\mathrm{b}} \pm 0.18$ & 0.01 \\
C20:3 & $1.14^{\mathrm{a}} \pm 0.06$ & $0.73^{\mathrm{b}} \pm 0.03$ & 0.01 \\
C20:4 & $5.45^{\mathrm{a}} \pm 0.32$ & $3.33^{\mathrm{b}} \pm 0.28$ & 0.02 \\
C20:5 & $0.29^{\mathrm{A}} \pm 0.02$ & $0.13^{\mathrm{B}} \pm 0.01$ & $<0.01$ \\
C22:4 & $1.10^{\mathrm{a}} \pm 0.07$ & $0.76^{\mathrm{b}} \pm 0.04$ & 0.01 \\
C22:5 & $2.96^{\mathrm{A}} \pm 0.14$ & $2.07^{\mathrm{B}} \pm 0.19$ & $<0.01$ \\
C22:6 & $3.05^{\mathrm{a}} \pm 0.32$ & $1.70^{\mathrm{b}} \pm 0.10$ & 0.02 \\
\hline ab:A.B & &
\end{tabular}

$\mathrm{a}, \mathrm{b} ; \mathrm{A}, \mathrm{B}$ Difference determined using Tukey's test; letters in lowercase (a,b) and uppercase $(\mathrm{A}, \mathrm{B})$ denote $P<0.05$ and $P<0.01$, respectively. ${ }^{1}$ Fatty acid composition was calculated as percentage of total fatty acids.

${ }^{2}$ Differentiated goat mammary epithelial cells were incubated with T0901317 at $0,0.01,0.1$, and $1.0 \mu M$ for $48 \mathrm{~h}$ (final concentration, dissolved in dimethyl sulfoxide; Sigma, St. Louis, MO). The control group $(0 \mu M)$ was treated with the same amount $(1 \mu \mathrm{L} / \mathrm{mL}$ medium $)$ of dimethyl sulfoxide as the T0901317-treated group.

${ }^{3}$ Long-chain PUFA contained C20:3, C20:4, C20:5, C22:4, C22:5, and C22:6.
As a key metabolic enzyme, DGAT catalyzes the conversion of diacylglycerol and fatty acyl-CoA into TAG. Two isoforms of DGAT have been characterized in the mammary gland: DGAT1 and DGAT2. The relative mRNA abundance of DGAT2 was very low in bovine mammary tissue and its expression was not affected by lactation, whereas DGAT1 had a relatively high abundance of mRNA and its expression increased as lactation progressed (Bionaz and Loor, 2008), and DGAT1 genetic variants are reported to be strongly associated with fat yield and composition in cows (Bovenhuis et al., 2015; Tăbăran et al., 2015). In the present study, we found that both DGAT1 and DGAT2 had a similar mRNA abundance in GMEC (Supplemental Table S1, https://doi.org/10.3168/jds.2018-15538), and the expression of DGAT2 increased in T0901317-treated cells compared with the control. It is now possible to conclude with our data whether activation of LXR increased transcription of the DGAT2 isoform directly or indirectly (i.e., through SREBP1).

Expression of AGPAT6 was increased upon transactivation of LXR. The Agpat6 has a high expression in the mammary epithelium of mice, and Agpat6 $^{-/-}$mice exhibited a striking defect in lactation accompanied by a dramatic decrease in the size and number of lipid droplets within mammary epithelial cells and depletion of diacylglycerol and TAG in the milk (Beigneux et al., 2006). Different from our observation, the use of siRNA specific for SREBF1 did not affect AGPAT6 expression in bovine mammary cells (Ma and Corl, 2012; OppiWilliams et al., 2013).

In addition, the expression of genes involved in lipid droplet formation, with the exclusion of $X H D$, was increased when LXR was activated. Perilipin 2 and perilipin 3 are 2 milk fat droplet proteins (Ogg et al., 2004; Ma and Corl, 2012); perilipin 2 is reported to be colocalized on the surface of lipid droplets (McIntosh et al., 2012) and is essential for the formation of milk fat lipid droplets and lactation, as demonstrated in mice (Russell et al., 2011). Studies to date have revealed that PLIN2 is mainly regulated transcriptionally by PPAR and LXR in monogastrics (Fan et al., 2009; Kotokorpi et al., 2010; Kang et al., 2015), indicating that the regulatory role of SREBP1 in milk fat droplet formation or secretion is not as strong as fatty acid synthesis, desaturation, elongation, and TAG synthesis. Using the free web-based tool Lasagna (Lee and Huang, 2013), we analyzed the promoter region of sheep PLIN2 for SREBP1 and LXR (NR1H2:RXR in Jaspar core matrices) response elements. We observed that the most significant enriched response elements were related to LXR, but the software also revealed several significant enriched response elements for SREBP1. 


\section{LXR and the Cross-Talk Among Transcriptional Regulators}

Data generated in bovine mammary tissue indicated potential cross-talk between several transcriptional factors in the control of the milk fat synthesis transcriptional network (Bionaz and Loor, 2008; Bionaz et al., 2013). A role of PPAR $\gamma$ in controlling expression of genes related to milk fat synthesis is emerging (Bionaz et al., 2013), but no role of PPAR $\alpha$ in mammary tissue has been reported for bovines or goats even though the mRNA abundance of PPARA is greater than the mRNA abundance of PPARG in bovine mammary tissue (Bionaz et al., 2013). Our data (Supplemental Table S1, https://doi.org/10.3168/jds.2018-15538) support a similar mRNA abundance proportion between PPAR isotypes in GMEC; however, our data indicated that expression of the 2 PPAR isotypes is not controlled by LXR, and a tendency for a contrasting effect of LXR and PPAR $\gamma$ is present in GMEC. However, the significance of this observation is unclear.

\section{LXR Activation Promotes Formation of UFA in GMEC}

Mammary tissue actively desaturates long-chain fatty acids and produces UFA, especially long-chain MUFA, from long-chain SFA (Bauman et al., 2006). The $\Delta^{9}$-desaturase protein coded by $S C D 1$ plays a central role in such activity. A strong association between SCD activity and concentration of MUFA in milk was detected in bovines (Conte et al., 2010). In our previous study in GMEC, we observed that the upregulation in expression of $S C D 1$ was strongly associated with an increase in the total proportion of $\mathrm{C} 16: 1$ and $\mathrm{C} 18: 1$ (Shi et al., 2012; Takahashi et al., 2013). In the present study, activation of LXR strongly upregulated the transcription of many milk fat synthesis-related genes, but the larger effect was observed for the expression of $S C D 1$ (Figure 3). Thus, the increase in the proportion of C16:1 and C18:1 and decreased proportion of C16:0 and C18:0 by activation of LXR in the present study can be due to an increase in activity of $S C D 1$.

\section{CONCLUSIONS}

In summary, our data indicate that activation of LXR by T0901317 enhanced transcription of SREBP1, increased the transcription of most of the milk fat synthesis-related genes, augmented the intracellular amount of TAG, and increased the desaturation of long-chain fatty acids in GMEC. The data suggest that most of the observed effects after activation of LXR are SREBP1 mediated. A model summarizing the findings from the present experiment is reported in
Supplemental Figure S3 (https://doi.org/10.3168/jds .2018-15538). Overall, results from the present study provide strong evidence that LXR and SREBP1 are key regulators of de novo fatty acid and TAG synthesis in goat mammary tissue. In addition, the use of reporter construct and measurement of gene expression using a specific LXR activator can provide insight into the role of LXR in milk fat synthesis. However, the use of point mutations or specific deletions can provide more robust proof.

\section{ACKNOWLEDGMENTS}

This research was jointly supported by National Natural Science Foundation of China (31702100, 31601915; Beijing, China) and the Transgenic New Species Breeding Program of China (2014ZX08009-051B; Beijing, China).

\section{REFERENCES}

Bauman, D. E., I. H. Mather, R. J. Wall, and A. L. Lock. 2006. Major advances associated with the biosynthesis of milk. J. Dairy Sci. 89:1235-1243.

Beigneux, A. P., L. Vergnes, X. Qiao, S. Quatela, R. Davis, S. M. Watkins, R. A. Coleman, R. L. Walzem, M. Philips, K. Reue, and S. G. Young. 2006. Agpat6-A novel lipid biosynthetic gene required for triacylglycerol production in mammary epithelium. J. Lipid Res. 47:734-744.

Bionaz, M., S. Chen, M. J. Khan, and J. J. Loor. 2013. Functional role of PPARs in ruminants: Potential targets for fine-tuning metabolism during growth and lactation. PPAR Res. 2013:684159.

Bionaz, M., and J. J. Loor. 2008. Gene networks driving bovine milk fat synthesis during the lactation cycle. BMC Genomics 9:366.

Bionaz, M., J. Osorio, and J. J. Loor. 2015. Triennial Lactation Symposium: Nutrigenomics in dairy cows: Nutrients, transcription factors, and techniques. J. Anim. Sci. 93:5531-5553.

Bovenhuis, H., M. H. Visker, H. J. van Valenberg, A. J. Buitenhuis, and J. A. van Arendonk. 2015. Effects of the DGAT1 polymorphism on test-day milk production traits throughout lactation. J. Dairy Sci. 98:6572-6582.

Calkin, A. C., and P. Tontonoz. 2010. Liver $\mathrm{x}$ receptor signaling pathways and atherosclerosis. Arterioscler. Thromb. Vasc. Biol. 30:1513-1518.

Chen, G., G. Liang, J. Ou, J. L. Goldstein, and M. S. Brown. 2004. Central role for liver $\mathrm{X}$ receptor in insulin-mediated activation of Srebp-1c transcription and stimulation of fatty acid synthesis in liver. Proc. Natl. Acad. Sci. USA 101:11245-11250.

Conte, G., M. Mele, S. Chessa, B. Castiglioni, A. Serra, G. Pagnacco, and P. Secchiari. 2010. Diacylglycerol acyltransferase 1, stearoylCoA desaturase 1 , and sterol regulatory element binding protein 1 gene polymorphisms and milk fatty acid composition in Italian Brown cattle. J. Dairy Sci. 93:753-763.

Darimont, C., O. Avanti, I. Zbinden, P. Leone-Vautravers, R. Mansourian, V. Giusti, and K. Mace. 2006. Liver X receptor preferentially activates de novo lipogenesis in human preadipocytes. Biochimie $88: 309-318$.

Dif, N., V. Euthine, E. Gonnet, M. Laville, H. Vidal, and E. Lefai. 2006. Insulin activates human sterol-regulatory-element-binding protein-1c (SREBP-1c) promoter through SRE motifs. Biochem. J. 400:179-188.

Eberlé, D., B. Hegarty, P. Bossard, P. Ferre, and F. Foufelle. 2004. SREBP transcription factors: Master regulators of lipid homeostasis. Biochimie 86:839-848. 
Fan, B., S. Ikuyama, J. Q. Gu, P. Wei, J. Oyama, T. Inoguchi, and J. Nishimura. 2009. Oleic acid-induced ADRP expression requires both AP-1 and PPAR response elements, and is reduced by Pycnogenol through mRNA degradation in NMuLi liver cells. Am. J. Physiol. Endocrinol. Metab. 297:E112-E123.

Foretz, M., C. Pacot, I. Dugail, P. Lemarchand, C. Guichard, X. Le Liepvre, C. Berthelier-Lubrano, B. Spiegelman, J. B. Kim, P. Ferre, and F. Foufelle. 1999. ADD1/SREBP-1c is required in the activation of hepatic lipogenic gene expression by glucose. Mol. Cell. Biol. 19:3760-3768

Han, C., J. W. Wang, L. Li, L. Wang, and Z. X. Zhang. 2009. The role of LXR alpha in goose primary hepatocyte lipogenesis. Mol. Cell. Biochem. 322:37-42.

Harvatine, K. J., Y. R. Boisclair, and D. E. Bauman. 2009. Recent advances in the regulation of milk fat synthesis. Animal 3:40-54.

Horton, J. D., J. L. Goldstein, and M. S. Brown. 2002. SREBPs: Activators of the complete program of cholesterol and fatty acid synthesis in the liver. J. Clin. Invest. 109:1125-1131.

Horton, J. D., N. A. Shah, J. A. Warrington, N. N. Anderson, S. W. Park, M. S. Brown, and J. L. Goldstein. 2003. Combined analysis of oligonucleotide microarray data from transgenic and knockout mice identifies direct SREBP target genes. Proc. Natl. Acad. Sci. USA 100:12027-12032.

Ishimoto, K., H. Nakamura, K. Tachibana, D. Yamasaki, A. Ota, K. Hirano, T. Tanaka, T. Hamakubo, J. Sakai, T. Kodama, and T. Doi. 2009. Sterol-mediated regulation of human lipin 1 gene expression in hepatoblastoma cells. J. Biol. Chem. 284:22195-22205.

Joseph, S. B., B. A. Laffitte, P. H. Patel, M. A. Watson, K. E. Matsukuma, R. Walczak, J. L. Collins, T. F. Osborne, and P. Tontonoz. 2002. Direct and indirect mechanisms for regulation of fatty acid synthase gene expression by liver X receptors. J. Biol. Chem. 277:11019-11025

Kamisuki, S., Q. Mao, L. Abu-Elheiga, Z. Gu, A. Kugimiya, Y. Kwon, T. Shinohara, Y. Kawazoe, S. Sato, K. Asakura, H. Y. Choo, J. Sakai, S. J. Wakil, and M. Uesugi. 2009. A small molecule that blocks fat synthesis by inhibiting the activation of SREBP. Chem. Biol. 16:882-892.

Kang, Y., S. Hengbo, L. Jun, L. Jun, Z. Wangsheng, T. Huibin, and S. Huaiping. 2015. PPARG modulated lipid accumulation in dairy GMEC via regulation of ADRP gene. J. Cell. Biochem. 116:192201.

Kotokorpi, P., N. Venteclef, E. Ellis, J. A. Gustafsson, and A. Mode. 2010. The human ADFP gene is a direct liver-X-receptor (LXR) target gene and differentially regulated by synthetic LXR ligands. Mol. Pharmacol. 77:79-86.

Lee, C., and C. H. Huang. 2013. LASAGNA: A novel algorithm for transcription factor binding site alignment. BMC Bioinformatics $14: 108$

Lehmann, J. M., S. A. Kliewer, L. B. Moore, T. A. Smith-Oliver, B. B Oliver, J. L. Su, S. S. Sundseth, D. A. Winegar, D. E. Blanchard, T. A. Spencer, and T. M. Willson. 1997. Activation of the nuclear receptor LXR by oxysterols defines a new hormone response pathway. J. Biol. Chem. 272:3137-3140.

Lengi, A. J., and B. A. Corl. 2010. Short communication: Identification of the bovine sterol regulatory element binding protein$1 \mathrm{c}$ promoter and its activation by liver X receptor. J. Dairy Sci. 93:5831-5836.

Li, J., J. Luo, H. Wang, H. Shi, J. Zhu, Y. Sun, K. Yu, and D. Yao 2015a. Adipose triglyceride lipase regulates lipid metabolism in dairy goat mammary epithelial cells. Gene 554:125-130.

Li, J., J. Luo, J. J. Zhu, Y. T. Sun, D. W. Yao, H. B. Shi, and W. Wang. 2015b. Regulation of the fatty acid synthase promoter by liver X receptor alpha through direct and indirect mechanisms in goat mammary epithelial cells. Comp. Biochem. Physiol. B Biochem. Mol. Biol. 184:44-51.

Li, X., Y. Li, W. Yang, C. Xiao, S. Fu, Q. Deng, H. Ding, Z. Wang, G. Liu, and X. Li. 2014. SREBP-1c overexpression induces triglycerides accumulation through increasing lipid synthesis and decreasing lipid oxidation and VLDL assembly in bovine hepatocytes. J. Steroid Biochem. Mol. Biol. 143:174-182.
Liang, G., J. Yang, J. D. Horton, R. E. Hammer, J. L. Goldstein and M. S. Brown. 2002. Diminished hepatic response to fasting/ refeeding and liver $\mathrm{X}$ receptor agonists in mice with selective deficiency of sterol regulatory element-binding protein-1c. J. Biol. Chem. 277:9520-9528.

Lin, X. Z., J. Luo, L. P. Zhang, W. Wang, H. B. Shi, and J. J. Zhu. 2013. MiR-27a suppresses triglyceride accumulation and affects gene mRNA expression associated with fat metabolism in dairy goat mammary gland epithelial cells. Gene 521:15-23.

Luo, Y., and A. R. Tall. 2000. Sterol upregulation of human CETP expression in vitro and in transgenic mice by an LXR element. J. Clin. Invest. 105:513-520.

Ma, L., and B. A. Corl. 2012. Transcriptional regulation of lipid synthesis in bovine mammary epithelial cells by sterol regulatory element binding protein-1. J. Dairy Sci. 95:3743-3755.

Mangelsdorf, D. J., C. Thummel, M. Beato, P. Herrlich, G. Schutz, K. Umesono, B. Blumberg, P. Kastner, M. Mark, P. Chambon, and R. M. Evans. 1995. The nuclear receptor superfamily: The second decade. Cell 83:835-839.

McFadden, J. W., and B. A. Corl. 2010. Activation of liver X receptor (LXR) enhances de novo fatty acid synthesis in bovine mammary epithelial cells. J. Dairy Sci. 93:4651-4658.

McIntosh, A. L., S. Senthivinayagam, K. C. Moon, S. Gupta, J. S. Lwande, C. C. Murphy, S. M. Storey, and B. P. Atshaves. 2012. Direct interaction of Plin2 with lipids on the surface of lipid droplets: A live cell FRET analysis. Am. J. Physiol. Cell Physiol. 303:C728C742.

Mohammad, M. A., and M. W. Haymond. 2013. Regulation of lipid synthesis genes and milk fat production in human mammary epithelial cells during secretory activation. Am. J. Physiol. Endocrinol. Metab. 305:E700-E716.

Ogg, S. L., A. K. Weldon, L. Dobbie, A. J. Smith, and I. H. Mather 2004. Expression of butyrophilin (Btn1a1) in lactating mammary gland is essential for the regulated secretion of milk-lipid droplets. Proc. Natl. Acad. Sci. USA 101:10084-10089.

Okazaki, H., J. L. Goldstein, M. S. Brown, and G. Liang. 2010. LXRSREBP-1c-phospholipid transfer protein axis controls very low density lipoprotein (VLDL) particle size. J. Biol. Chem. 285:68016810

Oppi-Williams, C., J. K. Suagee, and B. A. Corl. 2013. Regulation of lipid synthesis by liver X receptor alpha and sterol regulatory element-binding protein 1 in mammary epithelial cells. J. Dairy Sci. 96:112-121

Osorio, J. S., J. Lohakare, and M. Bionaz. 2016. Biosynthesis of milk fat, protein, and lactose: Roles of transcriptional and posttranscriptional regulation. Physiol. Genomics 48:231-256.

Owen, J. L., Y. Zhang, S. H. Bae, M. S. Farooqi, G. Liang, R. E. Hammer, J. L. Goldstein, and M. S. Brown. 2012. Insulin stimulation of SREBP-1c processing in transgenic rat hepatocytes requires p70 S6-kinase. Proc. Natl. Acad. Sci. USA 109:16184-16189.

Peet, D. J., S. D. Turley, W. Ma, B. A. Janowski, J. M. Lobaccaro, R. E. Hammer, and D. J. Mangelsdorf. 1998. Cholesterol and bile acid metabolism are impaired in mice lacking the nuclear oxysterol receptor LXR alpha. Cell 93:693-704.

Raghow, R., C. Yellaturu, X. Deng, E. A. Park, and M. B. Elam. 2008. SREBPs: The crossroads of physiological and pathological lipid homeostasis. Trends Endocrinol. Metab. 19:65-73.

Ramakers, C., J. M. Ruijter, R. H. L. Deprez, and A. F. M. Moorman. 2003. Assumption-free analysis of quantitative real-time polymerase chain reaction (PCR) data. Neurosci. Lett. 339:62-66.

Repa, J. J., G. Liang, J. Ou, Y. Bashmakov, J. M. Lobaccaro, I. Shimomura, B. Shan, M. S. Brown, J. L. Goldstein, and D. J. Mangelesdorf. 2000a. Regulation of mouse sterol regulatory element-binding protein-1c gene (SREBP-1c) by oxysterol receptors, LXRalpha and LXRbeta. Genes Dev. 14:2819-2830.

Repa, J. J., S. D. Turley, J. A. Lobaccaro, J. Medina, L. Li, K. Lustig, B. Shan, R. A. Heyman, J. M. Dietschy, and D. J. Mangelsdorf 2000b. Regulation of absorption and ABC1-mediated efflux of cholesterol by RXR heterodimers. Science 289:1524-1529. 
Rudolph, M. C., J. Monks, V. Burns, M. Phistry, R. Marians, M. R. Foote, D. E. Bauman, S. M. Anderson, and M. C. Neville. 2010. Sterol regulatory element binding protein and dietary lipid regulation of fatty acid synthesis in the mammary epithelium. Am. J. Physiol. Endocrinol. Metab. 299:E918-E927.

Russell, D. W. 1999. Nuclear orphan receptors control cholesterol catabolism. Cell 97:539-542.

Russell, T. D., J. Schaack, D. J. Orlicky, C. Palmer, B. H. Chang, L. Chan, and J. L. McManaman. 2011. Adipophilin regulates maturation of cytoplasmic lipid droplets and alveolae in differentiating mammary glands. J. Cell Sci. 124:3247-3253.

Shi, H. B., J. Luo, Y. Zhu, Z. Q. Wang, and W. S. Zhao. 2012. Cloning, sequence analysis and over-expression of SCD gene of dairy goat. Zhongguo Nong Ye Ke Xue 45:5091-5101.

Shi, H. B., C. H. Zhang, Z. A. Xu, X. F. Xu, Z. B. Lv, J. Luo, and J. J. Loor. 2017. Nuclear receptor subfamily 1 group H member 2 (LXRB) is the predominant liver $\mathrm{X}$ receptor subtype regulating transcription of 2 major lipogenic genes in goat primary mammary epithelial cells. J. Dairy Sci. 100:6743-6752.

Shi, H. B., W. S. Zhao, J. Luo, D. W. Yao, Y. T. Sun, J. Li, H. P. Shi, and J. J. Loor. 2014. Peroxisome proliferator-activated receptor gamma1 and gamma2 isoforms alter lipogenic gene networks in goat mammary epithelial cells to different extents. J. Dairy Sci. 97:5437-5447.

Shimano, H. 2001. Sterol regulatory element-binding proteins (SREBPs): Transcriptional regulators of lipid synthetic genes. Prog. Lipid Res. 40:439-452.

Tăbăran, A., V. A. Balteanu, E. Gal, D. Pusta, R. Mihaiu, S. D. Dan, A. F. Tabaran, and M. Mihaiu. 2015. Influence of DGAT1 K232A polymorphism on milk fat percentage and fatty acid profiles in Romanian Holstein cattle. Anim. Biotechnol. 26:105-111.

Takahashi, Y., A. Shinoda, N. Furuya, E. Harada, N. Arimura, I. Ichi, Y. Fujiwara, J. Inoue, and R. Sato. 2013. Perilipin-mediated lipid droplet formation in adipocytes promotes sterol regulatory element-binding protein-1 processing and triacylglyceride accumulation. PLoS One 8:e64605.

Takeuchi, Y., N. Yahagi, Y. Izumida, M. Nishi, M. Kubota, Y. Teraoka, T. Yamamoto, T. Matsuzaka, Y. Nakagawa, M. Sekiya, Y. Iizuka, K. Ohashi, J. Osuga, T. Gotoda, S. Ishibashi, K. Itaka, K. Kataoka, R. Nagai, N. Yamada, T. Kadowaki, and H. Shimano. 2010. Polyunsaturated fatty acids selectively suppress sterol regulatory element-binding protein-1 through proteolytic processing and autoloop regulatory circuit. J. Biol. Chem. 285:11681-11691.

Talukdar, S., and F. B. Hillgartner. 2006. The mechanism mediating the activation of acetyl-coenzyme A carboxylase-alpha gene transcription by the liver X receptor agonist T0-901317. J. Lipid Res. $47: 2451-2461$.
Tontonoz, P., J. B. Kim, R. A. Graves, and B. M. Spiegelman. 1993. ADD1: A novel helix-loop-helix transcription factor associated with adipocyte determination and differentiation. Mol. Cell. Biol. 13:4753-4759.

Vandesompele, J., K. De Preter, F. Pattyn, B. Poppe, N. Van Roy, A. De Paepe, and F. Speleman. 2002. Accurate normalization of real-time quantitative RT-PCR data by geometric averaging of multiple internal control genes. Genome Biol. 3:RESEARCH0034.

Vedin, L. L., S. A. Lewandowski, P. Parini, J. A. Gustafsson, and K. R. Steffensen. 2009. The oxysterol receptor LXR inhibits proliferation of human breast cancer cells. Carcinogenesis 30:575-579.

Wakil, S. J., and L. A. Abu-Elheiga. 2009. Fatty acid metabolism: Target for metabolic syndrome. J. Lipid Res. 50(Suppl.):S138-S143.

Wang, W., J. Luo, Y. Zhong, X. Z. Lin, H. B. Shi, J. J. Zhu, J. Li, Y. T. Sun, and W. S. Zhao. 2012. Goat liver X receptor alpha, molecular cloning, functional characterization and regulating fatty acid synthesis in epithelial cells of goat mammary glands. Gene 505:114-120.

Xu, H. F., J. Luo, H. P. Wang, H. Wang, T. Y. Zhang, H. B. Tian, D. W. Yao, and J. J. Loor. 2016a. Sterol regulatory element binding protein-1 (SREBP-1)c promoter: Characterization and transcriptional regulation by mature SREBP-1 and liver X receptor alpha in goat mammary epithelial cells. J. Dairy Sci. 99:1595-1604

Xu, H. F., J. Luo, W. S. Zhao, Y. C. Yang, H. B. Tian, H. B. Shi, and M. Bionaz. 2016b. Overexpression of SREBP1 (sterol regulatory element binding protein 1) promotes de novo fatty acid synthesis and triacylglycerol accumulation in goat mammary epithelial cells. J. Dairy Sci. 99:783-795.

Yao, D. W., J. Luo, Q. Y. He, H. F. Xu, J. Li, H. B. Shi, H. Wang, Z. Chen, and J. J. Loor. 2016. Liver X receptor alpha promotes the synthesis of monounsaturated fatty acids in goat mammary epithelial cells via the control of stearoyl-coenzyme A desaturase 1 in an SREBP-1-dependent manner. J. Dairy Sci. 99:6391-6402.

Zhang, X., J. Liu, W. Su, J. Wu, C. Wang, X. Kong, J. A. Gustafsson, J. Ding, X. Ma, and Y. Guan. 2014. Liver X receptor activation increases hepatic fatty acid desaturation by the induction of SCD1 expression through an LXRalpha-SREBP1c-dependent mechanism. J. Diabetes 6:212-220.

Zhang, Y., S. R. Breevoort, J. Angdisen, M. G. Fu, D. R. Schmidt, S. R. Holmstrom, S. A. Kliewer, D. J. Mangelsdorf, and I. G. Schulman. 2012. Liver LXR alpha expression is crucial for whole body cholesterol homeostasis and reverse cholesterol transport in mice. J. Clin. Invest. 122:1688-1699.

Zhu, J. J., J. Luo, W. Wang, K. Yu, H. B. Wang, H. B. Shi, Y. T. Sun, X. Z. Lin, and J. Li. 2014. Inhibition of FASN reduces the synthesis of medium-chain fatty acids in goat mammary gland. Animal 8:1469-1478. 